\title{
A PROSPECTIVE COMPARATIVE STUDY OF INCIDENCE, CLINICAL MANIFESTATION, PROGNOSIS AND OUTCOME OF DUODENAL ULCER AND ILEAL ULCER PERFORATION IN OUR INSTITUTE
}

\author{
1 Professor, Department of General Surgery, CMCH. \\ ${ }_{2}^{2}$ Assistant Professor, Department of General Surgery, $\mathrm{CMCH}$. \\ 3Junior Resident, Department of General Surgery, $\mathrm{CMCH}$. \\ 4Junior Resident, Department of General Surgery, $\mathrm{CMCH}$. \\ 5Junior Resident, Department of General Surgery, CMCH.
}

Raghupathy1, Lakshmypathy2, Arikrishnan Vaithiswaran ${ }^{3}$, Alex Franklin 4 , Sathish Kailasam ${ }^{5}$

\section{ABSTRACT}

\section{BACKGROUND}

Perforated peptic ulcer or ileal ulcer is a serious complication of ulcers with potential risk of grave complications. There is paucity of published reports on perforated peptic ulcer disease and ileal ulcer disease in our local environment. This study was conducted to evaluate the clinical presentation, management and outcome of patients with both ulcer perforations in our setting and to identify predictors of outcome of these patients.

\section{MATERIALS AND METHODS}

This study was a prospective study aimed at evaluating the clinical profile, aetiology and optimal surgical management of patients with duodenal and ileal perforation.

\section{RESULTS}

Duodenal and ileal perforation cases were taken for study. About 48 cases of duodenal perforation and 12 cases of ileal perforation were studied. Aetiology, presentation, comorbid illness, age and sex wise distribution, morbidity and mortality were analysed.

\section{CONCLUSION}

The study showed that duodenal ulcer perforation had a better outcome in terms of morbidity and mortality than ileal ulcer perforation

\section{KEYWORDS}

Perforated Peptic Ulcers, Perforated Ileal Ulcers, Clinical Profile, Surgical Management, Outcome.

HOW TO CITE THIS ARTICLE: Raghupathy, Lakshmypathy, Vaithiswaran A et al. A prospective comparative study of incidence, clinical manifestation, prognosis and outcome of duodenal ulcer and ileal ulcer perforation in our institute. J. Evolution Med. Dent. Sci. 2016;5(81):6029-6033, DOI: 10.14260/jemds/2016/1361

\begin{abstract}
INTRODUCTION
Crisp's description of a perforated ulcer from 1843 would fit into any modern textbook as far as the symptomatology is concerned. However, other features of the disease and of the patients affected have changed markedly since then. During the nineteenth century, ulcer perforation was a rare disease that occurred mainly in young women, with the perforations located near the cardia of the stomach. During the first decade of the twentieth century, ulcer perforation incidence increased greatly, and there was an epidemic of ulcer perforations situated in the duodenum of middle-aged men.[1],[2],[3],[4],[5],[6]. Today, ulcer perforation incidence is stable or tends to decline, and most patients with ulcer perforations are elderly men and women, with perforations in the prepyloric and pyloric areas as frequent as perforations in the duodenum. Ulcer perforation was a lethal disease until surgical treatment was introduced at the turn of the century.
\end{abstract}

Financial or Other, Competing Interest: None.

Submission 28-07-2016, Peer Review 17-09-2016,

Acceptance 21-09-2016, Published 07-10-2016.

Corresponding Author:

Dr. Raghupathy,

Professor,

Department of General Surgery,

Chengalpattu Medical College and Hospital, Chengalpattu.

E-mail: dr.traghupathy@gmail.com

DOI: $10.14260 /$ jemds $/ 2016 / 1361$
Mikulicz sutured a perforated gastric ulcer for the first time in 1880, and suture is still the most common treatment for ulcer perforation.

The revolution in ulcer treatment that occurred with discovery of the role of Helicobacter pylori has not yet led to any detectable changes in incidence or treatment of ulcer perforation. Thus, ulcer perforation is still a surgical disease for which the possibility for improvement in prognosis lies with the general advances of acute surgery. The potential for prevention lies in better understanding of causal factors, which have not been known until lately but apparently differ somewhat from those of uncomplicated ulcer.[7],[8],[9],[10]

A rare disease during the nineteenth century, ulcer perforation incidence increased greatly at the turn of the twentieth century. Since then the Western world has seen an epidemic of duodenal perforations among young men that now seems to be waning. Ulcer perforation incidence has been studied over an extended period in western Scotland (19241963), the United Kingdom (1958-1983), and western Norway (1935-1990). These studies show fairly similar trends.[11],[12] In men, ulcer perforation incidence increased until about 1950 and declined thereafter. In women, the incidence was low and fairly stable until about 1950, from which time it slowly increased. Increasing age among ulcer perforation patients has been observed during this time span, with declining incidence among the young and increasing incidence among the elderly. 
Most of this temporal variation could be attributed to changing rates of duodenal ulcer in men, whereas rates of gastric ulcer perforation appears to have been fairly stable.

\section{AIMS AND OBJECTIVE}

To study the incidence, clinical manifestation, prognosis and outcome of duodenal ulcer and ileal ulcer perforation.

\section{MATERIALS AND METHODOLOGY}

A prospective study of duodenal ulcer vs. ileal ulcer perforation in terms of clinical manifestations, prognosis, and outcome has been made by the study of 60 patients of hollow viscus perforation, admitted in Chengalpattu Medical College Hospital during the period of April 2015-April 2016.

\section{Inclusion Criteria}

Patients presenting with hollow viscus perforation either duodenal or ileal above 12 yrs. of age. Patients who do consent for the study.

\section{Exclusion Criteria}

Patients below 12 yrs. of age. Patient who do not consent for the study.

Hollow viscus perforation other than duodenal or ileal sample Size-60 cases.

\section{STUDY METHOD}

Clinical history, clinical examination, diagnostic and therapeutic, biochemical investigations and diagnostic imaging. The data will be entered into a proforma which also includes the demographic data, therapeutic interventions and course in hospitalisation.

A study of clinical features, investigations, operative procedures performed, postoperative morbidity and mortality and outcome was done.

The above 60 cases of study were admitted as emergencies after which a detailed history was taken once the patients were stable. In critically ill patients, stabilisation was done first and history was taken later.

Clinical history regarding fever, pain, vomiting, abdominal distension, constipation and treatment prior to admission were taken. Vital signs, hydration, abdominal distension, tenderness, guarding and presence of free air were noted. Systemic examination was done.

\section{All patients included in the study underwent following} basic Investigations

1. $\mathrm{Hb} \%$

2. $\mathrm{BT} / \mathrm{CT}$

3. RBS

4. Blood urea and serum creatinine

5. Chest $x$ ray

6. Abdominal $\mathrm{x}$-ray erect

7. ECG

8. Widal test and

9. Blood culture.

Preoperative fluid resuscitation, electrolyte and antibiotic cover were given.[13],,[14],[15],[16] Following procedures were done, omental patch closure, simple two layered closure, resection and anastomosis and bilateral flank drain.

\section{OBSERVATION}

The study was conducted from April 2015-April 2016 from the acute abdomen cases of hollow viscus perforation, presented at Chengalpattu Medical College Hospital.
Duodenal and ileal perforation cases were taken for study. About 48 cases of duodenal perforation and 12 cases of ileal perforation were studied. Aetiology, presentation, comorbid illness, age and sex wise distribution, morbidity and mortality were analysed.

- Majority of cases occurred predominantly in the age group of 20-40 yrs. for both duodenal and ileal ulcer perforations.

- Male predominance over female is seen in ratio as 3:1.

- Duodenal ulcer perforations were single perforation, while two cases of ileal perforations were multiple.

- Nine out of 60 patients presented earlier in less than 24 hrs. duration while rest presented more than 2-3 days.

- Biliary and purulent peritonitis were found predominantly in duodenal perforation while faeculent perforation was found in majority of ileal perforation patients.

- Clinical examination in detail and plain x-ray abdomen erect proved useful in duodenal perforation and Widal proved useful in diagnosis of typhoid fever.

- Omental patch closure were predominantly opted for duodenal perforation cases and primary closure for ileal perforation cases.

- Other treatment opted serosal patch closure in two cases and flank drain in four cases.

- Resection anastomosis was done for two cases of ileal perforation and ileostomy with mucus fistula was done for a case of ileal enteric perforation.

- $\quad$ Rate of complication was high in ileal ulcer perforation of about $66 \%$ while it was $40 \%$ in duodenal perforation cases.

- Type of surgical procedure did not influence either morbidity or mortality.

- $\quad$ Lag period significantly influenced the outcome in both group of patients.

- Typhoid is the most common cause of ileal ulcer perforation.

- Septicaemia was the commonest complication in majority of duodenal perforation cases and chest infection in postoperative period was found in many of ileal ulcer perforations.

- Mortality was high in long duration of presentation, large perforation and associated comorbid illness.

- Prognosis was good in patients who presented early.

- Ileal perforation has got more morbidity in the form of postoperative complications like wound infection, respiratory infection, burst abdomen, and enterocutaneous fistula.

- Ileal perforation has more mortality than duodenal perforation.

- Mortality rate was $12.5 \%$ in case of duodenal perforation and it was $25 \%$ in case of ileal perforation.

- Morbidity was significantly influenced by age $>50$ yrs. hypoalbuminaemia, and diagnosis of typhoid as the cause for perforation. Mortality was significantly influenced by age $>50$ yrs., shock at the time of presentation and multiple sites of perforation.

Hence, the conclusion of the study showed that duodenal ulcer perforation had a better outcome in terms of morbidity and mortality than ileal ulcer perforation. 


\section{DISCUSSION}

Peptic ulcer disease (PUD) represents a worldwide health problem because of its high morbidity, mortality and economic loss. In the United States, approximately 5 million adults suffer annually from peptic ulcer disease and new cases with 4 million recurrences are reported each year. Globally, the incidence of peptic ulcer disease has fallen in recent years. Despite this and recent advances in both diagnosis and management of peptic ulcer disease, namely the improvement in endoscopic facilities, eradication of $\mathrm{H}$. pylori and the introduction of the proton pump inhibitors, complications such as peptic ulcer perforation remain a substantial healthcare problem.

This may be due to an increase in the risk factors for peptic ulcer complications. Peptic ulcer perforation is a serious complication which affects almost $2-10 \%$ of peptic ulcer patients on the average.[17],[18],[19],[20] Peptic ulcer perforation presents with an overall mortality of $10 \%$ although some authors report ranges between $1.3 \%$ and $20 \%$. Being a life threatening complication of peptic ulcer disease, it needs special attention with prompt resuscitation and appropriate surgical management if morbidity and mortality are to be avoided. The pattern of perforated PUD has been reported to vary from one geographical area to another depending on the prevailing socio-demographic and environmental factors. In the developing world, the patient population is young with male predominance, patients present late, and there is a strong association with smoking. In the west, the patients tend to be elderly and there is a high incidence of ulcerogenic drug ingestion.

The diagnosis of perforated PUD poses a diagnostic challenge in most of cases. The spillage of duodenal or gastric contents into peritoneal cavity causing abdominal pain, shock, peritonitis, marked tenderness and decreased liver dullness offers little difficulty in diagnosis of perforations. The presence of gas under the diaphragm on plain abdominal erect X-ray is diagnostic in $75 \%$ of the cases. Since the first description of surgery for acute perforated peptic ulcer disease, many techniques have been recommended.

The recent advances in antiulcer therapy have shown that simple closure of perforation with omental patch followed by eradication of $\mathrm{H}$. Pylori is a simple and safe option in many centres and have changed the old trend of truncal vagotomy and drainage procedures. The definitive operation for perforated PUD is performed by few surgeons. Delay in diagnosis and initiation of surgical treatment of perforated PUD has been reported to be associated with high morbidity and mortality after surgery for perforated PUD.[21],[22] Early recognition and prompt surgical treatment of perforated PUD is of paramount importance if morbidity and mortality associated with perforated PUD are to be avoided. A successful outcome is obtained by prompt recognition of the diagnosis, aggressive resuscitation and early institution of surgical management.

Little work has been done on the surgical management of perforated peptic ulcer disease in our local environment despite increase in the number of admissions of this condition. The aim of this study was to describe our experience on the surgical management of perforated peptic ulcer disease in our local environment outlining the incidence, clinical presentation, management and outcome of patients with peptic ulcer perforation in our setting and to identify predictors of outcome of these patients.[23],[24],[25]
Perforation of the bowel especially the typhoid perforation is a serious complication and remains a significant surgical problem in developing nations. It is usually associated with high mortality and morbidity as it occurs mostly in underdeveloped countries in places where medical facilities are not readily available. Perforation of terminal ileum is a cause for obscure peritonitis, heralded by exacerbation of abdominal pain associated with tenderness, rigidity and guarding, most pronounced over right iliac fossa. However, for many patients in a severe toxic state, there may be obscured clinical features with resultant delays in diagnosis and adequate surgical intervention.[26],[27],[28],[29]

The present study was taken to review our experience of clinical profile and management of terminal ileal perforation over past 7 years.

Non-traumatic terminal ileal perforation is still common as a cause for obscure peritonitis in developing and underdeveloped world although in west it is quite rare. The terminal ileal perforation presents a diagnostic dilemma to the surgeon. Laparotomy is usually carried out late often suspecting a perforated appendicitis or a duodenal ulcer.

The mean age in our study was higher than other studies as the children below 12 years were excluded from the study and causes other than typhoid perforations were considered. The clinical features were similar to any other acute abdominal condition. The decision for a laparotomy was mainly clinical supplemented by investigations. However, no single investigation was specific.

The delay in operation since the estimated time of perforation was mainly prehospital. This is due to the fact that there most of the cases came from remote areas where the medical facilities are scarce. In cases of trauma, usually there is no difficulty in management since the tissues are healthy and patients present in good clinical state Typhoid fever is a predominant cause of nontraumatic perforation in developing countries. Typhoid fever, a severe febrile infectious disease caused primarily by Salmonella typhi occurs in areas where poor socioeconomic levels and unsanitary environmental conditions prevail.

After ingesting contaminated food, multiplication of bacteria occurs in the reticuloendothelial system during an incubation period of 1-14 days; clinical manifestations start with bacteraemia, high-grade fever, signs of systemic sepsis with characteristic normal or low blood counts and anaemiathe reason for low incidence of leucocytosis in our study.

Later the bacteria become localised in Peyer's patches. These undergo swelling and ulceration that can progress to capillary thrombosis and subsequent necrosis. These ulcerations are always located on the antimesenteric border of the intestine and may perforate, usually in $3^{\text {rd }}$ week of disease. An increase in titre of agglutinins against the somatic (O) and flagellar $(\mathrm{H})$ antigens of $\mathrm{S}$ typhi occurs (Basis for Widal test). The gut in typhoid fever is oedematous and friable (Especially last $60 \mathrm{~cm}$ ).

There may be one or several perforations and many other impending perforations, which makes the surgery difficult. Nonspecific inflammation of the terminal ileum was another predominant cause. In such cases, the operative findings were similar to that of typhoid fever but no laboratory evidence of the disease was found.

The clinical picture of tuberculous perforation will be that of a diffuse peritonitis and a chest radiograph showing radiological manifestations of tuberculosis. The most common site is the terminal ileum and intraoperative differentiation 
from Crohn's disease is difficult. These causes are extremely rare in West where Crohn's disease, foreign bodies, perforated diverticula and radiation enteritis are important causes. Late presentation, delay in operation ( $>48 \mathrm{hrs}$.), multiple perforations and drainage of copious quantities of pus and faecal material from the peritoneal cavity adversely affected the incidence of faecal fistula and subsequent mortality.

The peritoneal fluid content and the delay in operationperforation time also determine the severity of contamination and friability of gut. Various surgical procedures have been used for distal ileal perforations with variable results. Unfortunately, no matter what procedure is used postoperative mortality and morbidity remains high. The most catastrophic complication being the faecal fistula and the wound dehiscence. As depicted simple debridement and closure of the perforation is most commonly employed procedure in our setup but in severely contaminated cases with friable terminal ileum (those with delayed presentation, multiple perforations, faecaloid peritonitis), obviously something more than mere closure of perforations needs to be done to reduce the incidence of most deadly complication like faecal fistula. Resection anastomosis carried a high morbidity and mortality. Ileostomy would have been ideal but its maintenance in our underprivileged and the need for second operation discouraged us from its frequent use.

In such circumstances, end-to-side ileotransverse anastomosis with closure of distal stump is a better procedure. Ulcer perforation epidemiology has changed greatly throughout this century, largely owing to an epidemic of ulcer perforation in specific birth cohorts. Subjects born after the turn of the century have carried a high risk for ulcer perforation throughout their lives. The increasing ulcer perforation risk among the elderly today is related to ageing of these high risk cohorts; in younger generations the incidence is decreasing. Thus, ulcer perforation appears to be a slowly vanishing disease in our society. The distinct cohort phenomenon suggests that factors during early life contribute to determining susceptibility to ulcer perforation throughout adult life.

Age-related vulnerability to $\mathrm{H}$. pylori infection has been suggested as a possible early life factor of importance. Smoking seems to be a causal factor of major importance for ulcer perforation today, and a smaller proportion of ulcer perforations seem to be related to the use of NSAIDs. ${ }^{[30]}$ When it comes to treatment of ulcer perforation, modern times have allowed treatment of elderly patients with associated severe diseases-the ulcer perforation patients we usually meet today. However, lethality after ulcer perforation is still relatively high, representing a potential for improvement. There are indications that modern health care, with many professional groups involved and extensive possibilities for preoperative diagnostic measures available, is hampered by time-consuming routines. With ulcer perforation the prognosis is clearly related to efficiency of treatment; limiting the treatment delay to within 12 hours is likely to improve life expectancy after ulcer perforation.

Terminal ileal perforation should be considered as a possibility in obscure peritonitis. In developing countries, enteric perforation is a strong possibility. Early diagnosis and treatment avoids extensive procedures and is associated with lower morbidity and mortality.
The preoperative diagnosis is usually made in an endemic country except in patients who are moribund; there has to be a high level of suspicion. Investigations aid in diagnosis but no single investigation is diagnostic. Nonspecific inflammation and tuberculosis are other causes in developing countries.

The operative findings are typical with most enteric perforations on the antimesenteric border of terminal $60 \mathrm{~cm}$ of ileum. The operative management consists of liberal peritoneal lavage with closure of perforation. However, in the patients where the terminal ileum is grossly inflamed with multiple perforations, perforation-operation delay $>48$ hours, faecaloid peritonitis; something more than mere closure of perforation needs to be done and end-to-side ileotransverse anastomosis is a better procedure.

\section{CONCLUSION}

The study showed that duodenal ulcer perforation had a better outcome in terms of morbidity and mortality than ileal ulcer perforation.

\section{REFERENCES}

1. Türkdoğan $\mathrm{MK}$, Hekim $\mathrm{H}$, Tuncer $\mathrm{I}$, et al. The epidemiological and endoscopic aspects of peptic ulcer disease in Van region. Eastern Journal of Medicine 1999;4(1):6-9.

2. Isenberg JI, McQuaid KR, Laine L, et al. Acid-peptic disorders. Chap 61. In: Textbook of gastroenterology. Yamada T. edr. J B Lippıncott Comp., Philadelphia: 1991:1241-98.

3. Elnagib E, Mahadi SEI, Ahmed ME, et al. Perforated peptic ulcer in Khartoum. Khartoum Medical Journal 2008;1(2):62-4.

4. Hayat KS, Ul-Haq MI, Akhtar AS. Perforated peptic ulcer: a review of 36 cases. Professional Med J 2011;18(1):124-7.

5. Makela JT, Kiviniemi H, Ohtonen P, et al. Factors that predict morbidity and mortality in patients with perforated peptic ulcers. Eur J Surg 2002;168(8-9):44651.

6. Montalvo-Javé EE, Corres-Sillas O, Athié-Gutiérrez C. Factors associated with postoperative complications and mortality in perforated peptic ulcer. Cir Cir 2011;79(2):141-8.

7. Testini M, Portincasa P, Piccinni G, et al. Significant factors associated with fatal outcome in emergency open surgery for perforated peptic ulcer. World J Gastroenterol 2003;9(10):2338-40.

8. Soll AH. Peptic ulcer and its complications. In: Feldman M, Scharschmidt BF, Sleisenger MH. eds. Sleisenger \& Fordtran's gastrointestinal and liver disease: pathophysiology, diagnosis, management. $6^{\text {th }}$ edn. Philadelphia, PA: WB Saunders 1998:620-78.

9. Rajesh V, Sarathchandra S, Smile SR. Risk factors predicting operative mortality in perforated peptic ulcer disease. Trop Gastroenterol 2003;24(3):148-50.

10. Hermansson M, von Holstein SC, Zilling T. Surgical approach and prognostic factors after peptic ulcer perforation. Eur J Surg 1999;165(6):566-72.

11. Boey J, Choi SK, Poon A, et al. Risk stratification in perforated duodenal ulcers. A prospective validation of predictive factors. Ann Surg 1987;205(1):22-6.

12. Kudva MV, Thein-Htut. Profile of peptic ulcer disease in Malaysia. Sing Med J 1988;29(6):544-7. 
13. Hill AG. The management of perforated peptic ulcer in a resource poor environment. East Afr Med J 2001;78(7): 346-8.

14. Windsor JA, Hill AG. The management of perforated duodenal ulcer. N Z Med J 1995;108(994):47-8.

15. Cuschieri A. Disorders of stomach and duodenum. In: Cuschieri A, Steel RJC, Moosa AR. Essential surgical practice. $4^{\text {th }}$ edn. London: Arnold 2002:261-319.

16. Mehboob M, Khan JA, Shafiq-ur R, et al. Peptic duodenal perforation-an audit. JCPSP 2000;6:101-3.

17. de la Pena GC, Merquez R, Fakih F, et al. Simple closure or vagotomy and pyloroplasty for the treatment of a perforated duodenal ulcer: comparison of results. Dig Surg 2000;17(3):225-8.

18. Visick AH. Measured radical gastrectomy. Review of 505 operations for peptic ulcer. Lancet 1948;251(6501): 551-5.

19. Schein M, Saadia R, Decker GA. Perforated peptic ulcer at the J. G. Strijdom hospital. A retrospective study of 99 patients. S Afr Med J 1986;70(1):21-3.

20. Mieny CJ, Kopelowitz W, Colsen P. Management of perforated peptic ulcers. S Afr Surg 1974;12(1):27-9.

21. Evers BM. Small intestine. In: Townsend CM, RD Beauchamp RD, Evers BM, et al. eds. Sabiston textbook of Surgery. 18 ${ }^{\text {th }}$ edn. 2008; P. 1307.
22. Hosoglu S, Aldemir M, Akalin S, et al. Risk factors for enteric perforation in patients with typhoid fever. Am J Epidemiol 2004;160(1):46-50.

23. Chalya PL, Mabula JB, Koy M, et al. Typhoid intestinal perforations at a university teaching hospital in northwestern Tanzania: a surgical experience of 104 cases in a resource limited setting. World Journal of Emergency Surgery 2012;7:4.

24. Singh H, Mishra A, Sharma D, et al. A simple prognostic scoring system for typhoid ileal perforation peritonitis. Tropical Doctor 2010;40(4):203-7.

25. Sharma S, Kotru M, Batra M, et al. Limitations in the role of ulcer edge biopsy in establishing the aetiology of nontraumatic small bowel perforation. Tropical Doctor 2009;39(3):137-41.

26. Saxe JM, Cropsey R. Is operative management in treatment of perforated typhoid? Am J Surg 2005;189(3):342-4.

27. Ibrahim M, Getso KI, Yashuwa AH, et al. Single-layer closure of typhoid enteric perforation: our experience. African Journal of Paediatric Surgery 2013;10(2):167-71.

28. Kaul BK. Operative management of typhoid perforation in children. Int Surg 1975;60(8):407-10.

29. Chambers CE. Perforation of the ileum. Arch Surg 1972;105(4):550-2.

30. Kim JP, Oh SK, Jarrett F. Management of ileal perforation due to typhoid fever. Ann Surg 1975;181(1):88-91. 